\title{
The reluctant celebrity
}

\author{
A reclusive Russian \\ claims to have solved \\ a century-old
}

mathematical problem

- but his enigmatic

personality is adding

a fresh dimension to

the proof-checking

process. Emily Singer

reports.

t takes guts for a young Russian to stride into the heart of the US mathematical establishment after claiming to have solved a problem that has baffled the discipline's finest minds for decades. But by the time that Grigory 'Grisha' Perelman, a 30 -something recluse, arrived to talk at the Massachusetts Institute of Technology (MIT) in April 2003, it was clear that there was some substance behind his bravura.

Five months before, in a posting on the Internet ${ }^{1}$, Perelman claimed to have proved the geometrization conjecture, a theory crucial for understanding three-dimensional surfaces. This would automatically prove the more famous Poincaré conjecture, which has stumped mathematicians for 100 years ${ }^{2}$. The world's top mathematicians had tried to pick holes in his argument - and although their job was far from complete, they already suspected that Perelman was onto something big.

"Every few years, someone claims to have solved the Poincaré conjecture. It is usually a chore to go through and find the problem. But in this case it was clear there were new and brilliant ideas," says Tom Mrowka, a mathematician at MIT who has studied Perelman's work. "It was so original. Even if there was a gap near the end, it was a big deal."

When Perelman gave his talks at MIT, both to a broad audience and to a smaller group of mathematicians who had spent several months studying his work, he had answers for every question

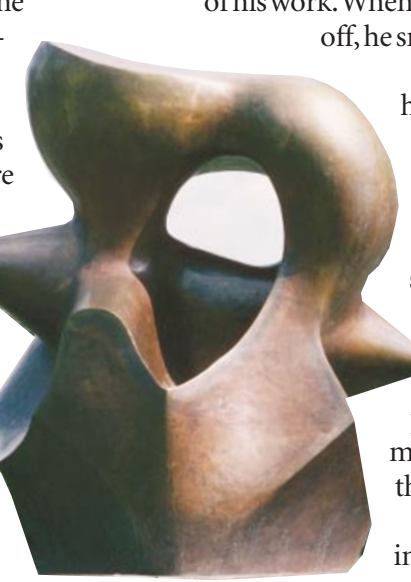

Mathematically this Henry Moore sculpture is the same as a doughnut. that came up. "It was clear he had thought about all these issues before," says Mrowka. "He'd either point out that it was a trivial question or he'd have an answer."

The media soon got wind of the potential significance of Perelman's achievement. An article about his work appeared in The New York Times in mid-April, and when Perelman lectured at the Courant Institute of Mathematical Sciences in New York two weeks later, reporters mingled with mathematicians in the audience. This time, Perelman was much less effusive. He refused to answer reporters' questions or speculate about the implications of his work. When a photographer's flash went off, he snapped: "Don't do that!"

Within weeks Perelman had returned to Russia, evidently annoyed at the uninvited publicity. He ignored a flurry of job offers and apparently has no plans to submit his work to a peerreviewed journal. He has also shown no interest in a US\$1-million prize that awaits the mathematician who finally proves the Poincaré conjecture.

Why did Perelman react in this way to the acclaim generated by his work? It's hard to say. He talks about little other than mathe- matics, even with those who count themselves as his friends. Colleagues have only theories for his reclusive behaviour. And e-mails from Nature, requesting an interview for this article, went unanswered.

\section{Scratching the surface}

Perelman's work focuses on the geometrical properties of three-dimensional surfaces. In mathematical terms, the thin film that makes up a soap bubble is a two-dimensional surface that curves round to enclose a threedimensional space. Similarly, there is a three-dimensional equivalent of the bubble's surface, called a three-sphere. Understanding such shapes could help mathematicians solve a host of topological problems, and perhaps even describe the shape of the Universe.

Nineteenth-century mathematicians had shown that any closed two-dimensional surface can be described - at a fundamental level - as one of two basic shapes: a sphere or a 'doughnut' with one or more holes. An egg is, in essence, the same as a smooth sphere; a coffee mug is a doughnut. Mathematically, an important characteristic separates spheres from doughnuts. A loop stretched around a sphere can always be shrunk down to a point - just as an elastic band round an egg can be pulled tight to a single point without losing contact with the egg's surface. This is not possible for a doughnut - a loop passing through the doughnut's hole cannot be pulled to a point without cutting through the doughnut 
